\title{
PROGRAM “MINDFUL PARENTING” UNTUK MENURUNKAN AFEK NEGATIF PADA IBU YANG MEMILIKI ANAK RETARDASI MENTAL
}

\author{
Martaria Rizky Rinaldi \\ Universitas Mercu Buana Yogyakarta \\ martariarizky@mercubuana-yogykarta.ac.id
}

\begin{abstract}
Abstrak
Mengasuh anak yang mengalami retardasi mental berhubungan dengan munculnya permasalahan fisik dan psikologis pada ibu. Hal ini meningkatkan munculnya afek negatif yang tinggi. Intervensi dengan berbasis mindfulness terbukti dapat membantu untuk meningkatkan kebahagiaan. Penelitian ini bertujuan untuk menguji pengaruh program "Mindful Parenting" untuk menurunkan afek negatif pada ibu yang memiliki anak retardasi mental. Penelitian ini menggunakan desain one-group pretestposttest design. Pengukuran afek negatif dilakukan dengan menggunakan skala afek negatif. Program "Mindful Parenting" diikuti oleh sepuluh ibu yang memiliki anak retardasi mental. Partisipan mengikuti mengikuti delapan sesi program "Mindful parenting" dalam empat kali pertemuan. Analisis dengan menggunakan uji Wilcoxon Signed Rank Test menunjukkan hasil yang signifikan $(\mathrm{Z}=-2,312$, $\mathrm{p}=0,01)$. Hal ini menunjukkan bahwa program "Mindful Parenting" dalam penelitian ini terbukti dapat menurunkan afek negatif pada ibu yang memiliki anak dengan retardasi mental..
\end{abstract}

Kata Kunci: afek negatif, mindfulness, mindful parenting, retardasi mental

\section{MINDFUL PARENTING PROGRAM FOR DECREASING NEGATIVE AFFECT ON MOTHERS OF CHILDREN WITH INTELLECTUAL DISABILITY}

\author{
Martaria Rizky Rinaldi \\ Universitas Mercu Buana Yogyakarta \\ martariarizky@mercubuana-yogykarta.ac.id
}

\begin{abstract}
Parenting child with intellectual disability is associated with physical and psychological problems that influence mother's negative affect. The evidence is show that mindfulness based intervention can increase happiness. The aim of this study is to examine the effectiveness of "Mindful parenting" program in decreasing negative affects on mother who has child with intellectual disability. This study uses a one-group pretest-posttesttt design. "Mindful Parenting" program was administered to ten mothers of children with intellectual disability. Participant attend 8 sessions of "Mindful parenting" program in four meetings. Analysis using Wilcoxon signed rank test showed significance result $(\mathrm{Z}=$ $2,312, p=0,01)$. It conclude that there was significant effect of "Mindful parenting" program on reduces negative affects on mothers of children with intellectual disability.
\end{abstract}

Keywords: intellectual disability, mindfulness, mindful parenting, negative affect 


\section{PENDAHULUAN}

Memiliki anak yang sehat dan normal merupakan harapan setiap keluarga. Kelahiran dan diagnosis adanya disabilitas pada anak menjadi sebuah pengalaman traumatis dan berpengaruh signifikan terhadap kehidupan, emosi dan perilaku anggota keluarga (Ergün \& Ertem, 2012; Samuel, Rillotta, \& Brown, 2012; Willingham-Storr, 2014). Meskipun demikian, terdapat dampak positif dan negatif dari hadirnya anak dengan disabilitas dalam sistem keluarga (Reichman, Corman, \& Noonan, 2008). Dampak positifnya yaitu akan memperluas wawasan, meningkatkan kepekaan terhadap kekuatan batin, meningkatkan kebersamaan keluarga, dan mendorong hubungan dengan komunitas atau institusi keagamaan. Dampak negatifnya yaitu meningkatkan waktu perawatan dan pengeluaran dalam keluarga, menyebabkan tuntutan fisik dan emosi, dan perlunya penyediaan kebutuhan yang berhubungan dengan membesarkan anak dengan disabilitas. Dampak yang terjadi tergantung pada kondisi dan tingkat keparahan, seperti kondisi fisik, emosi, dan finansial yang diperlukan, serta ketersediaan sumber daya dalam keluarga. Anak dengan disabilitas menunjukkan beban yang berat bagi keluarga dalam aspek psikologis, fisik, sosial, dan ekonomi (Cantwell, Muldoon, \& Gallagher, 2014;
Gallagher \& Hannigan, 2014; Ouyang, dkk., 2014; Raina dkk., 2005; Woodman, Mawdsley, \& Hauser-Cram, 2015).

Dalam penelitian ini, disabilitas difokuskan pada retardasi mental. Dalam DSM-5 (American Psychiatric Association, 2013) dijelaskan retardasi mental adalah disabilitas yang memiliki karakteristik kurangnya fungsi kognitif dan perilaku adaptif yang meliputi kemampuan sosial dan ketrampilan praktis sehari-hari. Disabilitas ini munculnya pada usia di periode perkembangan.

Anak dengan retardasi mental mengalami berbagai permasalahan, antara lain perilaku agresif, perilaku melukai diri sendiri, perilaku stereotip, gangguan kecemasan, gangguan mood, permasalahan makan, dan permasalahan tidur (Sturmey \& Didden, 2014). Permasalahan yang terjadi pada anak memberikan dampak juga terhadap keluarga. Perilaku dan permasalahan pada anak membuat ibu membutuhkan waktu yang lebih banyak dalam perawatan (Padeliadu, 1998; Schieve, Boulet, Kogan, Van NaardenBraun, \& Boyle, 2011). Hal ini membuat perilaku dan beban pengasuhan anak berpengaruh signifikan terhadap kesehatan fisik dan psikologis yang merawatnya (Diwan, Chovatiya, \& Diwan, 2011).

Kesehatan mental dari orang tua anak yang mengalami retardasi mental pun lebih buruk daripada orang tua anak tanpa 
retardasi mental (Totsika, Hastings, Emerson, Berridge, \& Lancaster, 2011). Hal ini dikarenakan orang tua dan keluarga dari anak yang mengalami retardasi mental mengalami situasi yang lebih stres dan menguras emosi dalam kehidupan seharihari (Baker et al., 2003; Hastings \& Beck, 2004). Orang tua yang memiliki anak dengan retardasi mental mengalami stres dalam pengasuhan yang lebih besar jika dibandingkan dengan orang tua yang memiliki anak normal (Craig dkk., 2016).

Peran jenis kelamin jelas terbukti berpengaruh dalam proses pengasuhan anak yang mengalami retardasi mental, ibu cenderung lebih mengalami stres dan tingkat kecemasan yang tinggi (Norlin \& Broberg, 2013; Seymour, Wood, Giallo, \& Jellett, 2013). Selain lebih mengalami stres, ibu juga mengalami permasalahan emosi, kurangnya tidur, dan rasa bersalah (Burke \& Hodapp, 2014; Findler, Klein Jacoby, \& Gabis, 2016; Glenn, Cunningham, Poole, Reeves, \& Weindling, 2009). Ibu dari anak retardasi mental juga cenderung lebih berisiko mengembangkan depresi (Singer, 2006). Tekanan dan permasalahan yang dialami banyak memunculkan afek negatif pada ibu.

Afek negatif adalah sebuah konsep yang merupakan gabungan perasaanperasaan yang menunjukkan distres emosional (Watson, Clark, \& Tellegen, 1998). Tingginya afek negatif menunjukkan banyaknya perasaan tidak nyaman secara subjektif pada diri individu. Suasana pengasuhan menjadi semakin tidak nyaman jika ibu mengalami banyak afek negatif, oleh karena itu perlu diberikan suatu intervensi untuk menurunkannya.

Intervensi yang telah terbukti dapat menurunkan afek negatif antara lain dengan mengungkapkan kebersyukuran (Emmons \& McCullough, 2003). Selain itu, intervensi yang dapat mempengaruhi afek yaitu mindfulnes. Mindfulness dapat meningkatkan emosi positif dan fleksibilitas dalam merespon, menurukan reaktivitas pikiran dan emosi, dan menurunkan afek negatif dan ruminasi (David \& Hayes, 2011 dalam Malaktaris, Lemons, Lynn, \& Condon, 2015).

Mindfulness adalah keadaan seseorang yang orang dapat memberikan perhatian tanpa terganggu pada suatu periode waktu, dengan tidak memberikan penilaian terhadap keadaan fisik, kognitif, dan pengalaman psikologis yang sedang berlangsung (Kabat-Zinn, 1994). Dalam keadaan mindful, orang tidak memberikan analisis kritis atau memberikan penilaian terhadap pengalaman yang dialami. Mindfulness berfokus pada perhatian yang berkesinambungan pada pengalaman yang mencakup peristiwa internal maupun eksternal (Brown \& Ryan, 2003; Brown, Ryan, Creswell, 2007). Pada mindfulness 
terdapat proses pengamatan kembali yang merujuk pada kapasitas seseorang untuk mengambil jarak pada pikiran dan emosinya (Shapiro, Carlson, Austin, \& Freedman, 2006). Hal ini mencakup perpindahan proses sadar individu. Individu yang awalnya kurang mengidentifikasi peristiwa mental (seperti pikiran dan emosi) menjadi lebih menyadari peristiwa tersebut. Individu yang lebih menyadari peristiwa (memiliki kesadaran yang tinggi) cenderung memiliki kondisi emosional yang positif.

Pengaruh mindfulness terhadap afek dijelaskan dengan tiga fungsi spesifik, yaitu menurunkan afek negatif, meningkatkan afek positif, dan mengubah respon individu jika mengalami afek negatif. Program MBSR (Davidson et al., 2003) dapat meningkatkan aktivasi otak depan kiri. Area ini berhubungan dengan afek positif. Penelitian Creswell, Way, Eisenberger, \& Lieberman (2007) terhadap pengaruh neurologis mindfulness menunjukkan bahwa individu yang memiliki skor mindfulness yang tinggi, lebih tidak reaktif terhadap stimulus yang menakutkan secara emosional dibandingkan dengan individu yang memiliki skor rendah. Hal ini diindikasikan oleh respon amigdala yang melemah dan peningkatan aktivasi prefrontal cortex (PFC) saat menghadapi stimulus. Amigdala merupakan bagian otak yang berfungsi mengirimkan peringatan adanya bahaya ataupun ancaman, sehingga dapat menyebabkan emosi negatif. PFC merupakan bagian otak yang berhubungan dengan fungsi yang lebih tinggi, seperti kesadaran, konsentrasi dan pengambilan keputusan. PFC bertugas menghalangi pesan yang dikirim oleh amigdala, sehingga tidak menimbulkan reaktivitas emosi negatif terhadap suatu stimulus. Individu yang mindful memiliki reaktivitas afek negatif yang lebih rendah dan afek positif yang lebih stabil dibandingkan individu yang tidak mindful ketika dihadapkan pada suatu stimulus yang negatif (Arch \& Craske, 2006).

Mindfulness telah terbukti dapat membantu mengatasi masalah kesehatan mental. Membawa mindfulness ke dalam pengasuhan (parenting) merupakan salah satu aplikasi dari mindfulness. Mindful parenting merupakan sebuah program adaptasi dari MBSR dan MBCT untuk ibu belajar menerapkan ketrampilan untuk dirinya sendiri dan untuk pengalamannya dalam merawat anak (Bögels \& Restifo, 2014). Kabat-Zinn \& Kabat-Zinn (dalam Bogels \& Restifo, 2014) mendefinisikan mindful parenting sebagai proses kreatif yang sedang berlangsung, bukan merupakan titik akhir. Hal ini melibatkan membawa kesadaran dengan sengaja dan tanpa penilaian sebaik mungkin di setiap saat. Ini mencakup menyadari proses 
internal, yaitu pikiran, emosi, dan sensasi tubuh, dan eksternal yaitu, anak, keluarga, rumah, dan budaya yang lebih luas.

Konsep utama dalam mindful parenting yaitu (1) kesadaran yang lebih besar pada dunia, perasaan, dan kebutuhan anak yang unik; (2) kemampuan yang lebih besar untuk hadir dan mendengarkan dengan penuh perhatian; (3) menyadari dan menerima apapun di setiap saat, baik menyenangkan ataupun tidak menyenangkan; (4) menyadari impuls reaktif pada diri dan belajar untuk merespon secara tepat dengan kejernihan dan kebaikan hati (Bogels \& Restifo, 2014). Orang tua yang mempraktikkan mindful parenting pada interaksinya dengan anak akan lebih tenang menghadapi perilaku negatif anak (Bogels, Lehtonen, \& Restifo, 2010), lebih konsisten dan mempunyai tujuan serta nilai yang jelas dalam pengasuhan (Duncan, Coatsworth, \& Greenberg, 2009). Mindful parenting juga meningkatkan interaksi positif antara orang tua dan anak, meningkatkan afek positif, dan menurunkan afek negatif, meningkatkan kepercayaan orang tua, dan meningkatkan kemampuan berbagi perasaan (Coastsworth, Duncan, Greenberg, \& Nix, 2010; Duncan dkk., 2009; Singh dkk., 2006; Singh dkk., 2010). Selain itu, mindful parenting dapat menjaga hubungan emosi dan fisik antara orang tua dan anak (Altmaier \& Maloney, 2007), meningkatkan fungsi orang tua dalam pengasuhan anak (Bogels dkk., 2010), penerimaan positif (MacDonald \& Hastings, 2010), kepuasan orang tua (Singh, dkk., 2007; Singh dkk., 2010), dan kebahagiaan pengasuhan (Singh, dkk., 2009).

Tujuan dari penelitian ini yaitu untuk mengetahui pengaruh program mindful parenting terhadap afek negatif ibu yang memiliki anak dengan retardasi mental. Hipotesis yang diajukan yaitu program "mindful parenting" dapat menurunkan afek negatif pada ibu yang memiliki anak dengan retardasi mental.

\section{METODE}

Partisipan dalam penelitian ini melibatkan 10 orang ibu yang memiliki anak retardasi mental. Karakteristik dari partisipan yaitu sebagai berikut: (1) ibu yang memiliki anak dengan retardasi mental, yang tergabung dalam komunitas orang tua yang memiliki anak berkebutuhan khusus, (2) ibu merupakan pengasuh utama anak dan tinggal bersama dengan anak yang mengalami retardasi mental, (3) mampu melakukan mobilisasi secara memadai untuk bergabung dalam proses intervensi, (4) mampu berbahasa Indonesia dengan baik secara lisan dan tertulis. 
Instrumen yang digunakan dalam penelitian ini yaitu skala afek negatif, lembar observasi dan buku harian.

Skala afek negatif yang digunakan dalam penelitian ini merupakan modifikasi dari skala afek yang disusun oleh Utami (2009) yang berdasarkan dari Watson dkk. (1998). Koefisien reliabilitas skala afek negatif $r=0,954$.

Buku harian disusun dengan tujuan untuk melihat perkembangan partisipan setiap harinya selama mengikuti program. Buku ini berisi pencatatan latihan pada saat di luar proses pelatihan (tugas rumah). Dalam buku harian juga berisi skala ukur diri mindful parenting dan skala ukur diri emosi harian.

Penelitian ini menggunakan pendekatan kuantitatif dengan desain eksperimen "the one group pretestposttesttt design" (Shadish, Cook, \& Campbell, 2002). Peneliti hanya menggunakan kelompok eksperimen yaitu kelompok yang menerima intervensi program Mindful parenting. Hal ini dikarenakan terbatasnya subjek penelitian yang dapat mengikuti seluruh rangkaian kegiatan pelatihan.

Intervensi dalam penelitian ini berupa program "mindful parenting", yaitu intervensi berbasis mindfulness yang diaplikasikan dalam pengasuhan. Program dilaksanakan dalam empat kali pertemuan dengan durasi sekitar 180 menit selama dua minggu.

\section{Analisis Data}

Proses analisis data pada penelitian ini dilakukan dengan menggunakan uji Wilcoxon Signed Rank Test. Uji Wilcoxon merupakan metode analisis statistik non parametrik dengan membandingkan dua sampel yang berhubungan (Corder \& Foreman, 2009).

\section{HASIL DAN PEMBAHASAN}

Hasil cek manipulasi dengan dengan menggunakan Wilcoxon signed rank-test diperoleh nilai $Z=-2,670$ dengan $p=0,004$. Hal ini mengindikasikan bahwa terdapat perbedaan keadaan atau ketrampilan mindful parenting antara sebelum dan sesudah diberikannya program "Mindful parenting".

Hasil analisis Wilcoxon signed ranktest terhadap afek negatif menunjukkan hasil yang signifikan $(Z=-2,805, p<0,05)$ pada sebelum dan sesudah diberikan perlakuan. Hal ini menunjukkan bahwa hipotesis dalam penelitian ini diterima. Terdapat penurunan afek negatif yang signifikan dari sebelum dan sesudah pemberian program "Mindful parenting".

Hasil penelitian ini membuktikan bahwa program "Mindful parenting" memberikan manfaat pada ibu yang memiliki anak dengan retardasi mental. Ibu mengalami lebih sedikit afek negatif 
setelah mengikuti program. Hasil ini sesuai dengan penelitian Turpyn \& Chaplin (2016) yaitu ibu lebih sedikit menunjukkan emosi negatif dalam pengasuhan dan menunjukkan lebih banyak emosi positif.

Afek negatif menunjukkan bahwa seseorang mengalami berbagai suasana hati yang tidak menyenangkan, seperti tertekan, merasa bersalah, atau marah. Tingginya afek negatif yang terjadi pada individu membuat individu merasakan emosi negatif (Diener, 2000). Hal ini berbeda dengan individu yang berada pada kondisi mindful. Individu yang mindful memiliki kemampuan yang lebih besar dalam mentoleransi pikiran, emosi dan pengalaman (Baer, 2003). Kemampuan toleransi yang meningkat membuat partisipan mengalami penurunan afek negatif secara signifikan.

Dengan program Mindful parenting memberikan ketrampilan pada ibu untuk mengasuh dengan penuh perhatian, tidak reaktif, dan menerima seluruh pengalaman pengasuhan tanpa penilaian (Duncan, 2009). Hasil dari penelitian ini menunjukkan bahwa ibu menjadi lebih menerima pengalaman pengasuhan tanpa memberikan penilaian-penilaian terhadap kondisi anak ataupun lingkungan sekitar.

Praktik mindfulness yang dilakukan membuat partisipan memiliki kesadaran yang lebih terhadap suatu pengalaman. Individu yang lebih menyadari peristiwa (memiliki kesadaran yang tinggi) cenderung memiliki kondisi emosional yang positif. Mindfulness memiliki pengaruh terhadap perkembangan kecerdasan emosi. Hal ini membuat individu dapat menerima emosi dengan lebih tepat dan dapat meregulasi emosi dengan efektif sehingga dapat meningkatkan kepuasan hidupnya (Caffey \& Hartman, 2008; Caffey, Hartman, Fredrickson, 2010; Schutte \& Malouff, 2011; Wang \& Kong, 2013). Fredrickson (dalam Brown, 2015) menjelaskan bahwa kondisi emosional yang positif dapat meningkatkan kemampuan dalam memproses dan menyimpan informasi baru, dan untuk membuat pola pikiran sehingga individu menjadi lebih positif dan kreatif.

Penelitian ini tidak terlepas dari ancaman-ancaman penelitian. Ancaman terhadap validitas internal pada penelitian ini yaitu history. Faktor sejarah (history) berupa peristiwa yang dialami partisipan dalam kehidupan pribadi yang mempengaruhi kondisi selama masa penelitian. Sejarah merupakan variabel lain di luar eksperimen yang tidak dapat dikontrol oleh peneliti, namun berpengaruh terhadap variabel tergantung (Morgan \& Morgan, 2009). Ancaman validitas tidak hanya pada validitas internal, namun juga pada validitas kesimpulan statistik. Ancaman pada validitas penyimpulan 
statistik yaitu unreliability of tratment implementation yang dilihat berdasarkan evaluasi buku harian partisipan. Partisipan penelitian tidak melakukan semua latihan meditasi mindfulness di rumah. Selain itu, partisipan juga tidak rutin mengaplikasikan mindful parenting dalam pengasuhan. Hal ini dapat menurunkan effect size (Shadish et al., 2002).

Keterbatasan dalam penelitian ini yaitu (1) kurangnya kontrol terhadap seleksi partisipan, misalnya usia anak dan pengalaman meditasi, (2) kurangnya kontrol yang kuat terhadap proses praktik mindfulness di rumah, sehingga tidak semua partisipan melakukan praktik mindfulness di rumah, (3) tidak dilakukan pengukuran kepribadian, padahal kepribadian merupakan salah satu faktor yang mempengaruhi kesejahteraan subjektif (Lucas \& Diener, 2009).

\section{KESIMPULAN}

$\begin{array}{rrr}\text { Secara } & \text { keseluruhan } & \text { dapat } \\ \text { disimpulkan bahwa program } & \text { "mindful }\end{array}$ parenting" dapat menurunkan afek negatif pada ibu yang memiliki anak retardasi mental. Dengan mindful parenting, ibu yang memiliki anak dengan retardasi mental dapat memiliki kesadaran yang lebih besar pada dunia, perasaan, dan kebutuhan anak yang unik; mampu untuk hadir dan mendengarkan anak dengan penuh perhatian; menyadari dan menerima apapun di setiap saat, baik menyenangkan ataupun tidak menyenangkan; dan menyadari impuls reaktif pada diri dan belajar untuk merespon secara tepat. Tujuan ini telah dapat dirasakan oleh partisipan penelitian. Hal ini tidak terlepas dari peningkatan kemampuan mindfulness yang signifikan pada partisipan. Kegiatan mindfulness berfokus pada keadaan saat ini dan terlibat pada pengalaman saat ini sehingga mempengaruhi peningkatan afek positif. Selain itu juga mindfulness mampu meningkatkan kemampuan toleransi pikiran, emosi dan pengalaman sehingga mempengaruhi penurunan afek negatif.

\section{DAFTAR PUSTAKA}

Altmaier, E., \& Maloney, R. (2007). An initial evaluation of a mindful parenting program. Journal of Clinical Psychology, 63(12), 12311238. doi: $10.1002 /$ jclp.

American Psychiatric Association. (2013). Diagnostic and statistical manual of mental disorders. Arlington. http://doi.org/10.1176/appi.books.97 80890425596.744053 .

Arch, J. J., \& Craske, M. G. (2006). Mechanisms of mindfulness : Emotion regulation following a focused breathing induction. Behaviour Research and Therapy 44, 1849-1858. doi: 10.1016/j.brat.2005.12.007

Baer, R. A. (2003). Mindfulness training as a clinical intervention: A conceptual and empirical review. Clinical Psychology: Science and Practice, 10, 125-143. 
Baker, B. L., McIntyre, L. L., Blacher, J., Crnic, K., Edelbrock, C., \& Low, C. (2003). Pre-school children with and without developmental delay: Behavior problems and parenting stress over time. Journal of Intellectual Disability Research, 47(4), 217-230.

Bögels, S. M., Lehtonen, A., \& Restifo, K. (2010). Mindful Parenting in Mental Health Care. Mindfulness, 1(2), 107-120. doi: 10.1007/s12671-0100014-5.

Bögels, S., \& Restifo, K. (2014). Mindful parenting: A guide for mental health practitioners. London: Springer. doi: 10.1007/978-1-4614-7406-7.

Brown, K. W. (2015). Mindfulness Training to Enhance Positive Functioning. Dalam Brown, K. W., Creswell, J. D., \& Ryan, R. M. Handbook of Mindfulness: Theory, Research, and Practice. New York: The Guilford Press.

Brown, K. W., \& Ryan, R. M. (2003). The benefits of being present: Mindfulness and its role in psychological well-being. Journal of Personality and Social Psychology, 84(4), 822-848.

Brown, K. W., Ryan, R. M., \& Creswell, J. D. (2007). Mindfulness: Theoretical foundations and evidence for its salutary effects. Psychological Inquiry, 18(4), 211-237.

Burke, M. M., \& Hodapp, R. M. (2014). Relating stress of mothers of children with developmental disabilities to family-school partnerships. Intellectual and Developmental Disabilities, 52(1), 13-23. http://doi.org/10.1352/19349556-52.1.13.

Cantwell, J., Muldoon, O. T., \& Gallagher, S. (2014). Social support and mastery influence the association between stress and poor physical health in parents caring for children with developmental disabilities. Research in Developmental Disabilities, 35(9), 2215-2223. http://doi.org/10.1016/j.ridd.2014.05 .012 .

Coatsworth, J. D., Duncan, L. G., Greenberg, M. T., \& Nix, R. L. (2010). Changing parent's mindfulness, child management skills and relationship quality with their youth: Results from a randomized pilot intervention trial. Journal of Child and Family Studies, 19(2), 203-217. http://doi.org/10.1007/s10826-0099304-8.

Compton, W.C., \& Hoffman, E. (2013). Positive Psychology: The Science of Happiness and Flourishing. Belmont, CA: Wadsworth Publishing.

Corder, G. W., \& Foreman, D. L. (2009). Nonparametric statistics for nonstatisticians: A step by step approach. Canada: John Wiley \& Sons, Inc.

Craig, F., Felicia, F., Giacomo, A. De, Margari, L., Frolli, A., Conson, M., ... Margari, F. (2016). Parenting stress among parents of children with Neurodevelopmental Disorders. Psychiatry Research, 242, 121-129. http://doi.org/10.1016/j.psychres.20 16.05.016.

Creswell, J. D., Way, B. M., Eisenberger, N. I., \& Lieberman, M. D. (2007). Neural Correlates of Dispotional Mindfulness During Affect Labelling. Psychosomatic Medicine, 69 : 6, 560-565. doi.org/10.1097/psy.0b013e3180f61 $71 \mathrm{f}$

Davidson, R. J., Kabat-zinn, J., Schumacher, J., Rosenkranz, M., Muller D, Santorelli SF, ... Sheridan 
J. F. (2003). Alterations in brain and immune function produced by mindfulness meditation. Psychosomatic Medicine, 65(4), 564-570. Diakses dari https://www.ncbi.nlm.nih.gov/pubm ed/12883106.

Diener, E. (2000). Subjective wellbeing: The science of happiness and a proposal for a national index. American Psychologist, 55(1), 34-43.

Diwan, S., Chovatiya, H., \& Diwan, J. (2011). Depression and Quality of Life in Mothers of Children with Cerebral Palsy. NJIRM 2011, 2, 1113.

Duncan, L. G., Coatsworth, J. D., \& Greenberg, M. T. (2009). A Model of Mindful Parenting: Implications for Parent-Child Relationships and Prevention Research. Clinical Child and Family Psychology Review, 12(3), 255-270. doi: 10.1007/s10567-009-0046-3.

Emmons, R. A., \& McCullough, M. E. (2003). Counting blessings versus burdens: An experimental investigation of gratitude and subjective well-being in daily life. Journal of Personality and Social Psychology, 84(2), 377-389.

Ergun, S., \& Ertem, G. (2012). Difficulties of mothers living with mentally disabled children. Journal of the Pakistan Medical Association, 62, 776-780.

Findler, L., Klein Jacoby, A., \& Gabis, L. (2016). Subjective happiness among mothers of children with disabilities: The role of stress, attachment, guilt and social support. Research in Developmental Disabilities, 55, 4454. http://doi.org/10.1016/j.ridd.2016.03 .006 .
Gallagher, S., \& Hannigan, A. (2014). Depression and chronic health conditions in parents of children with and without developmental disabilities: The growing up in Ireland cohort study. Research in Developmental Disabilities, 35(2), 448-454.

http://doi.org/10.1016/j.ridd.2013.11 .029 .

Glenn, S., Cunningham, C., Poole, H., Reeves, D., \& Weindling, M. (2009). Maternal parenting stress and its correlates in families with a young child with cerebral palsy. Child: Care, Health and Development, 35(1), 71-78. http://doi.org/10.1111/j.13652214.2008.00891.x.

Hastings R, \& Beck A (2004). Practitioner review: Stress intervention for parents of children with intellectual disabilities. Journal Child Psychology Psychiatri, 45, 1338-49.

Kabat-Zinn, J. (1994). Wherever you go, there you are: Mindfulness meditation in everyday life. New York: Hyperion.

Lucas, R. E., \& Diener, E. (2009). Personality and subjective wellbeing. In E. Diener (Ed.), Social indicators research series: Vol. 37. The science of well-being: The collected works of Ed Diener (pp. 75-102). New York, NY, US: Springer Science + Business Media.

MacDonald, E. E., \& Hastings, R. P. (2010). Mindful parenting and care involvement of fathers of children with intellectual disabilities. Journal of Child and Family Studies, 19(2), 236-240.

http://doi.org/10.1007/s10826-0089243-9.

Malaktaris, A., Lemons, P., Lynn, S. J., \& Condon, L. (2015). Chilling Out: Meditation, Relaxation, and Yoga. 
Dalam Lynn, S. J., O’Donohue, W. T., \& Lilienfeld, S. O (Eds). Health, happiness, and well-being: Better living through psychological science. London:Sage Publications, Inc.

Morgan, D.L., \& Morgan, R.K. (2009). Single-Case Research Methods for the Behavioral and Health Sciences. California: Sage Publications, Inc.

Norlin, D., \& Broberg, M. (2013). Parents of children with and without intellectual disability: Couple relationship and individual wellbeing. Journal of Intellectual Disability Research, 57(6), 552566. http://doi.org/10.1111/j.13652788.2012.01564.x.

Ouyang, L., Grosse, S. D., Riley, C., Bolen, J., Bishop, E., Raspa, M., \& Bailey, D. B. (2014). A comparison of family financial and employment impacts of fragile $\mathrm{X}$ syndrome, autism spectrum disorders, and intellectual disability. Research in Developmental Disabilities, 35(7), 1518-1527.

http://doi.org/10.1016/j.ridd.2014.04 .009 .

Padeliadu, S. (1998). Time demands and experienced stress in Greek mothers of children with Down's syndrome. Journal of Intellectual disability Research, 42, 144-153.

Raina, P., O'Donnell, M., Rosenbaum, P., Brehaut, J., Walter, S.D., Russell, D, ... Wood, E. (2005). The Health and Well-Being of Caregivers of Children With Cerebral Palsy. Pediatrics, 115(6), e626-e636. http://doi.org/10.1542/peds.20041689.

Reichman, N. E., Corman, H., \& Noonan, K. (2008). Impact of Child Disability on the Family. Maternal Child Helath Journal, 12, 679-683. http://doi.org/10.1007/s10995-0070307-z

Samuel, P. S., Rillotta, F., \& Brown, I. (2012). Review: The development of family quality of life concepts and measures. Journal of Intellectual Disability Research, 56(1), 1-16. http://doi.org/10.1111/j.13652788.2011.01486.x

Schieve, L. A., Boulet, S. L., Kogan, M. D., Van Naarden-Braun, K., \& Boyle, C. A. (2011). A population-based assessment of the health, functional status, and consequent family impact among children with Down syndrome. Disability and Health Journal, 4, 68-77.

Schutte, N., \& Malouff, J. (2011). Emotional intelligence mediates the relationship between mindfulness and subjective wellbeing. Personality and Individual Differences 50 (7), 1116 - 1119. https://doi.org/10.1016/j.paid.201 1.01 .037

Seymour, M., Wood. C., Giallo, R., \& Jellet. R. (2013). Fatigue, stress and coping in mothers of children an autism spectrum disorder. Jounal of Autism and Developmental Disorders, 43 (7), $1547 \quad$ - 1554 https://doi.org/10.1007/s10803012-1701-y

Shadish, W.R., Cook, T. D., \& Campbell, D. T. (2002). Experimental and QuasiExperimental Designs for Generalized Causal Inference. Boston, MA, US: Houghton, Mifflin and Company.

Shapiro, S.L., Carlson, L.E., Austin, J.A., \& Freedman, B. (2006). Mechanisms of mindfulness. Journal of Clinical Psychology, 


$$
\text { 62, 373-386. }
$$

Singer, G. H. S. (2006). Meta-Analysis of Comparative Studies of Depression in Mothers of Children With and Without Developmental Disabilities. American Association Mental Retardation American Journal On Mental Retardation, 155(3), 155-169.

http://doi.org/10.1352/08958017(2006)111[155:MOCSOD]2 $.0 . \mathrm{CO} ; 2$

Singh, N. N., Lancioni, G. E., Winton, A. S. W., Fisher, B. C., Wahler, R. G., Mcaleavey, K., ... Sabaawi, M. (2006). Mindful parenting decreases aggression, noncompliance, and self-injury in children with autism. Journal of Emotional and Behavioral Disorders, 14(3), 169-177. doi: 10.1177/10634266060140030401

Singh, N. N., Lancioni, G. E., Winton, A. S. W., Singh, J., Singh, A. N., Adkins, A. D., \& Wahler, R. G. (2010). Training in mindful caregiving transfers to parentchild interactions. Journal of Child and Family Studies, 19(2), 167-174. doi: 10.1007/s10826009-9267-9

Sturmey, P., \& Didden, R. (2014). Evidence-based practice and intellectual disabilities. West Sussex: John Wiley \& Sons, Ltd.

Totsika, V., Hastings, R. P., Emerson, E.,Berridge, D. M., \& Lancaster, G. A. (2011). Behavior problems at 5 years of age and maternal mental health in autism and intellectual disability. Journal of Abnormal Child Psychology, 39(8), 1137-1147. http://doi.org/10.1007/s10802011-9534-2

Turpyn, C.C., \& Chaplin, T.M. (2016).
Mindful Parenting and Parents' Emotion Expression: Effects on Adolescent Risk Behaviors. Mindfulness, 7(1): 246-254. doi: 10.1007/s12671-015-0440-5

Utami, M.S. (2009). Keterlibatan dalam kegiatan dan kesejahteraan subjektif mahasiswa. Jurnal Psikologi. Fakultas Psikologi Universitas Gadjah Mada, 36(2), 144-163.

Wang, Y., \& Kong, F. (2013). The Role of Emotional Intelligence in the Impact of Mindfulness on Life Satisfaction and Mental Distress. Social Indicators Research, 116 (3), $843 \quad-\quad 852$. https://doi.org/10.1007/s11205013-0327-6.

Watson, D., Clark, L. A., \& Tellegen, A. (1988). Development and validation of brief measures of positive and negative affect: The PANAS scales. Journal of Personality and Social Psychology, 54, 1063-1070.

Willingham-Storr, G. L. (2014). Parental experiences of caring for a child with intellectual disabilities: A UK perspective. Journal of Intellectual Disabilities: JOID, 18(2), 146158. http://doi.org/10.1177/17446295 14525132

Woodman, A. C., Mawdsley, H. P., \& Hauser-Cram, P. (2015). Parenting stress and child behavior problems within families of children with developmental disabilities: Transactional relations across 15 years. Research in Developmental Disabilities, 36, 246-276.

http://doi.org/10.1016/j.ridd.2014 .10 .011 